Borneo Journal of Sciences and Technology, Volume (1), Issue (2), Pages: 45-50

DOI: 10.35370/BJOST.2019.1.2-07

e-ISSN: 2672-7439

(C) 2019, UCTS Publisher.

Submitted: $21^{\text {st }}$ April 2019

Accepted: $15^{\text {th }}$ May 2019

Published: $31^{\text {st }}$ July 2019

\title{
The Distribution of Macaranga tanarius (L.) Mull. Arg. in Peninsular Malaysia
}

\author{
Rosdi Koter 1,2, Mohd Zaki Hamzah ${ }^{2}$,Nor Aini Abd Shukor ${ }^{2,3}$, Hazandy Abdul Hamid ${ }^{2,3}$, Wan Rasidah \\ Kadir $^{1}$, Patahayah Mansor ${ }^{1}$ and Mohd Zaki Isa ${ }^{1}$ \\ ${ }^{1}$ Forest Research Institute Malaysia (FRIM), 52109 Kepong, Selangor, Malaysia \\ ${ }^{2}$ Faculty of Forestry, University Putra Malaysia, 43400 UPM, Selangor, Malaysia \\ ${ }^{3}$ Laboratory of Sustainable Bioresources Management, Institute of Tropical Forestry and Forest Product, \\ Universiti Putra Malaysia, 43400 UPM, Selangor, Malaysia
}

\begin{abstract}
Macaranga tanarius distribution has been identified in a study conducted by almost all states in Peninsular Malaysia. Assessment on the distribution of M. tanarius was based on the records available and type specimens housed in three different herbarium namely the Kepong Herbarium (KEP) in Forest Research Institute Malaysia, the herbarium in the Faculty of Forestry in Universiti Putra Malaysia and the Herbarium Universiti Kebangsaan Malaysia. While field surveys were carried out from July 2012 until October 2013. There are 128 specimens were assessed from the three herbaria which made in the year of 1925 to 2005. Field surveys showed that $M$. tanarius can be found from the state of Perlis in the north, to the state of Johor in the south. From the observation, $M$. tanarius is a commonly found species along the highways and the road sides, whether as single individuals or as mono-stands. It can be seen growing together with other pioneer species of shrubs or trees. The study also shows the growing pioneer species in disturbed habitats and the creation of new space to meet before the displacement process other quality species grows in the forest opening. This study is first surveys involving M.tanarius species including the entire state in peninsular Malaysia. It is intended for the collection and distribution -related service information management for the study of phenology of collecting seeds to be planting material.
\end{abstract}

Keywords: Macaranga tanarius, tropical pioneer species, Peninsular Malaysia, distribution

\section{INTRODUCTION}

Macaranga is a large genus comprises of 380 species worldwide. It can be found in tropical Africa and Madagascar, in tropical Asia from India to Indo-China and throughout the Malesian region, northern Australia and the Pacific east to Fiji [1]. The center of diversity is found within Malesia of 160 species occurrence with highly number of endemism in Borneo and New Guinea. In Malaysia alone, there is about 27 species of Macaranga [2]. They are often found gregariously and may locally form pure stand. It can be seen almost everywhere, along the roadsides, in the forest edge, disturbed sites, degraded land and in swampy forest [3]. Despite the vast populations and the most commonly found, there were very few studies conducted on the genus, except several extensive work by Jumaat [4], Davies et al. [5] and Silk et al. [6], done in Sabah and Sarawak. In Peninsular Malaysia, there was no specific publication on Macaranga except for a few brief reports by Whitmore [2], Corner [3], Turner [7], and Zakaria et al [8].
Most Macaranga species are short-lived pioneers and form a characteristic element of a secondary forest. They are fast growing, dioecious, evergreen of small to medium-sized trees up to $30 \mathrm{~m}$ tall. A few Macaranga species are either facultative or obligate myrmecophytes. The latter group of species associated with ants for producing nutrients and nesting spaces, mainly in hollow twigs, in exchange for herbivore protections [9]. A few species were used as indicator species for the degree of disturbances to a forested area [10] as the genus is among the first to colonize a newly opened area.

M. tanarius is one of the Macaranga species reported to occur only in Peninsular Malaysia. It was among the most frequently found species in the studied area. Although the distribution of this species in the Malesian region as well as the Malayan region is recognized, little information is available on the distribution of this species except the study by Zakaria [8] in Penang Island. Therefore it is very interesting to focus on the distribution of this species in its current state. 


\section{The Distribution of Macaranga tanarius in Peninsular Malaysia}

The distribution of $M$. tanarius can be tabulated under several vegetation types and classification following the forest type category set by the Forestry Department of Peninsular Malaysia [11]:

1. Lowland area $(<300 \mathrm{~m})$

2. Hill land area $(301-750 \mathrm{~m})$

3. Upper hill land area $(>750 \mathrm{~m})$

The distribution of $M$. tanarius was identified in a study that covered almost every state in Peninsular Malaysia. The study also shows the growth of pioneer species in disturbed habitats before being displaced by other quality species. The study was also the first survey to involve this species throughout Peninsular Malaysia. Macaranga tree in Peninsular Malaysia is a pioneer plant that is well-known to grow in disturbed areas, such as logging forest area, mining area and other places which experienced disturbance caused by human activities [8]. This tree is a small to medium in size, and with many branches.

The objectives of this study is to evaluate the distribution pattern of $M$. tanarius in Peninsular Malaysia, and to produce a distribution map in comparison with the previously available data from the vouchers collected and kept in Kepong Herbarium (KEP).

\section{MATERIALS AND METHODS}

\section{Herbarium database}

Assessment on the distribution of $M$. tanarius was based on the records available and type specimens housed in three different herbarium namely the Kepong Herbarium (KEP) in Forest Research Institute Malaysia, the herbarium in the Faculty of Forestry in Universiti Putra Malaysia and the Herbarium Universiti Kebangsaan Malaysia. Data on the localities with precise longitudinal and latitudinal coordinates of each specimen were used to produce primary distribution map. Longitudinal and latitudinal coordinates of the localities of each herbarium specimen were entered into Rapid Data Entry (RDE) file and saved as dbf format, which could be used and read using ArcGIS 10.4 software. A total of 128 voucher specimens were assessed but only 60 with recorded locality were used in the field survey. Detailed examination on the specimens were also made for in situ identification in the field.

\section{Field survey}

The distribution study data was based on observation during field surveys. The field survey were carried out from 15 months from July 2012 until October 2013 in various states in Peninsular Malaysia. The surveys was carried out along the trunk roads i.e., the PLUS Highway, the East-West Highway and the federal roads in all states. All M. tanarius natural stands with more than 20 to 30 individuals found along the roadsides were recorded and voucher specimens was prepared (where available) and deposited in KEP Herbarium. The location of each site was mapped using Garmin GPS model series 62 and later transferred onto a digital land-use map. Status of the occurrence of the species recorded in the mentioned herbaria were also groundtrothed. Due to the logistics problem, the survey on islands was not conducted except for Langkawi Island and Penang Island was derived from a study conducted by Zakaria [8].

\section{Distribution map}

A map of distribution from collected data and herbarium sheet collection was prepared using ArcGIS 10.4 software. These data were entered in the Rapid Data Entry (RDE) file and saved as dbf format. The information was mapped onto the Peninsular Malaysia map available from the GIS Department, FRIM.

\section{RESULTS}

\section{Herbarium Specimens}

There are 128 specimens were assessed from the three herbaria ie KEP Herbarium, FRIM; UPM Herbarium and Herbarium UKM. Those collection were made in the year of 1925 to 2005 .

There are 106 voucher specimens of $M$. tanarius deposited in KEP Herbarium, collected from various locations in Malaysia including from the states of Sabah and Sarawak, and a few from Indonesia, Palawan Island, the Philippines, and Papua New Guinea. Out of the 106 specimens, only 42 of it were from Peninsular Malaysia. A close examination on the specimens showed that the earliest specimen collected was in Sumpitan, Perak in 1925.

There were four specimens of Macaranga assessed in the Universiti Putra Malaysia Herbarium but none was M.tanarius. In the Universiti Kebangsaan Malaysia Herbarium, there were 18 specimens of M.tanarius deposited. The oldest collection was made in 1970 in Fraser's Hill.

Based on the information from the specimens, most were collected or found in disturbed sites of the secondary forests or belukar of both lowland and hill forests, along the roadside. On the hill forest, it was commonly found at the hillside or at the flat side of the hill forest. It was also found near the river bank or along the riverside. Deep in the primary forests, such as in Ulu Muda Forest Reserve, this species was found growing along logging trails.

$M$. tanarius was also recorded and collected in the islands of Malaysia such as in Langkawi Island, Tioman Island, Sibu Island, Tengah Island and Penang 


\section{The Distribution of Macaranga tanarius in Peninsular Malaysia}

Island. It can be seen at the seaside or along the coastal side. It was also recorded growing on limestone hill forest.

M. tanarius adapted to various type of soils, from the ultrabasic soils to sandy beach soils. However, it was rarely found on peat swamp soil and heavy clay soil.

The species was found from the lowest altitude of $15 \mathrm{~m}$ a.s.l up to $600 \mathrm{~m}$ a.s.l. The highest altitude of the specimen collected was at $610 \mathrm{~m}$ a.s.1 in Penang Island, near the upper tunnel station of Penang Hill. The forest site was mentioned to be a secondary forest.

Out of the 60 specimens, $61 \%$ were collected from the lowland area which is below $300 \mathrm{~m}$ a.s.l. The most collected specimens were found in the altitude range of 101-200m. In total 60 specimens were provided with data on localities with detailed information on the longitudinal and latitudinal readings can be used to produce the distribution map. The distribution map of the herbarium specimens is mapped as in Figure 1.

\section{Field Survey}

A series of field surveys were conducted within a year period from July 2012 to October 2013, and covered along the trunk roads i.e., the PLUS Highway, the EastWest Highway and the federal roads in all states Peninsular Malaysia. Results from the survey show that M. tanarius can be found from the state of Perlis in the north, to the state of Johor in the south (Figure 1).

From the observation, $M$. tanarius is a commonly found species along the highways and the road sides, whether as single individuals or as mono-stands. It can be seen growing together with other pioneer species of shrubs or trees from the family Moraceae, Cannabaceae, Fabaceae, Sapotaceae and Euphorbiaceae such as Ficus sp., Trema orientalis, T. angustifolia, Leucena leucocepala, Alstonia sp., Sapium baccatum, Mallotus sp., and Acacias. M. tanarius was rarely found growing together with other Macaranga species except $M$. gigantea. However, both species were never observed to form a mixed stand. In a few locations, $M$. tanarius was found growing together with a monocot, Musa balbisiana (Musaceae).

$M$. tanarius population was found to be more concentrated in the northern part of the peninsular, and scarcely populated in the eastern region and the southern part of Johor. M. tanarius was found in various altitudes and soil types, and well distributed, except in the peat soil area south of Johor and in the BRIS areas from Pahang to Kelantan. The areas where less concentration of $M$. tanarius recorded are areas known for their poor soil quality. The distribution of $M$. tanarius in this study was similar to the previously collected specimens, however, there were more populations observed at higher altitude. M. tanarius was found at Gunung Jerai, Bukit Tinggi, Fraser's Hill,
Cameron Highland, Maxwell Hill and Genting Highland, at a range of altitudes below (Table 1).

In the current study, $M$. tanarius was found at elevation more than $1000 \mathrm{~m}$ a.s.l which was in Cameron Highland, Pahang, followed by Genting Highland at $900 \mathrm{~m}$ a.s.1, Bukit Tinggi at $758 \mathrm{~m}$ a.s.1., and Fraser's Hill at $677 \mathrm{~m}$ a.s.l. While in Gunung Jerai and Maxwell Hill, it was found at elevation up to $469 \mathrm{~m}$ a.s.1 and $320 \mathrm{~m}$ a.s.l., respectively. At these sites, $M$. tanarius was observed growing as individuals at open and flat areas. It was rarely observed growing on steep slopes.

At lower elevation, more $M$. tanarius populations were found in clumps, with some found forming a mono-stand. They were found in disturbed sites, or abandoned land which as earlier occupied by other invasive species such as Imperata sp., or Mimosa pigra, or other pioneer species. M. tanarius was also found in swampy sites, which experience seasonal flooding during heavy rain and monsoon season.

Several recorded locations on the establishment of M. tanarius taken from KEP Herbarium were revisited. In Ulu Muda Forest Reserve, the location was already occupied by other species and with new observations. $M$. tanarius was found in widely open site, near an old $\log$ yard site. Along the open trail of logging road, $M$. tanarius was found together with Sapium baccatum, Mallotus sp., and Trema sp.

In the previously located site at Kota Tinggi, urbanisation had taken place. No individual $M$. tanarius was observed. The condition is similar with other sites previously observed in Klang Valley. The sites were changed to other land use and $M$. tanarius were replaced with landscape trees. However, in several other urban locations, M. tanarius was kept as part of the landscape component.

M. tanarius has a short life rotation and very much affected by the canopy closure. This could be the reason why some of the trees were no longer found at their earlier sightings. Rapid land use change was also responsible to the absence of the species in its former sites.

In the hilly secondary forests, such as in Janda Baik, M. tanarius can be seen growing nearby the riverbank and at the fringe of the forest.

\section{DISCUSSION}

M. tanarius is a Macaranga species with wide distribution in Peninsular Malaysia. The species can be found scattered from the lowland to the upper hill forest, and up to the montane forest. It grows along forest fringes, along the roadsides, hillsides and mountain slopes. It is one of the most common Macaranga found in the Peninsular after M. gigantea. The spread of this species was found to be favored by disturbance and it rapidly colonised the gaps or margins 


\section{The Distribution of Macaranga tanarius in Peninsular Malaysia}

in the forest [12]. Due to its potential to spread and colonize rapidly, the species is categorized as an invasive species outside its native habitat [13]. However, in native habitat, its spreading and colonising habit proved to be beneficial in promoting natural regeneration in degraded and deforested land. The clustering habit of this species which forms a dense stand, impedes the growth of other vegetation. This clustering nature could be the result of seed dispersal mechanism. M. tanarius has both short- and longdistance dispersal behavior. Without animal vector, most seeds will fall within a short distance from the mother trees. Taylor [14], observed that a large proportion of Macaranga seedlings, including $M$. tanarius grew only a few meters away from the mother tree. Seeds of M. tanarius are too heavy to be dispersed by wind. Dispersal agents such as water and birds able to move the seeds farther away the mother tree.

The exclusion of other plants under the thickets of M. tanarius may also resulted from the allelopthatic interaction produced by the plant. The species is found to produce phytotoxin during leaf composition that inhibits the growth of several plants species [15]. Ecologically, the clustering behavior of $M$. tanarius in the long term may create favorable condition for nonpioneer species to establish.

M. tanarius grows in a variety of soil types including clay, loam, and sand [16]. In Peninsular, besides clayey, loamy and sandy soils, it is also found growing in limestone area, but hardly in peat soil. The sandy BRIS which is the dominant soil type in the east coast is not favorable to the growth of $M$. tanarius. BRIS soil is inherently poor in nutrient due to high leaching process, as well as high soil moisture surface of up to $50^{\circ} \mathrm{C}$ [17]. These extreme conditions hinder the growth of plants except those with high adaptability. $M$. tanarius favors high moisture condition and good soil to grow and establish. Peat soil, having low soil $\mathrm{pH}$, low micro- and macronutrient contents does not support growth of $M$. tanarius.

M. tanarius in Peninsular Malaysia is more diverse at low land areas. On the hill land area such as Cameron Highland, drastic construction especially on the widening of the road from Tapah had led to the dispersal of this species. Whitmore [2] found $M$. tanarius at $600 \mathrm{~m}$ a.s.1. Similar high altitude occurrence of $M$. tanarius was recorded from the specimens deposited at KEP Herbarium. The latest finding from survey shows that $M$. tanarius can be found as high as $1020 \mathrm{~m}$ a.s.1. This finding showed similar trend at other hill forests and mountain sites surveyed, i.e., Fraser's Hill, Penang Hill, Genting Highlands and Bukit Tinggi. The populations found at higher latitude compared to previously reported, may significantly be affected by the feeding behavior of $M$. tanarius seed dispersers, the birds. Even though no specific study has been conducted on the dispersal agents of this species yet, a few observations showed that certain birds' species visited $M$. tanarius and ate the fruits, and could be responsible for the long distance seed dispersal [14]. Climate change could have also played a role for the establishment of $M$. tanarius at higher elevation.

$M$. tanarius is a short-lived fast growing pioneer and its establishment may depend much on the microclimate conditions of an area. Even though it is a fast growing species, it is not as hardy as Acacia mangium which can establish and grow well in rocky sites or heavily degraded sites. Based on data from other countries, the life span of cultivated $M$. tanarius is less than 15 years [18] as they were cut down on purpose. Under natural conditions, $M$. tanarius can live well over 20 years. As a pioneer species that quickly fills any gap which allows light to penetrate the forest canopy, $M$. tanarius quickly disappears as more permanent species take over. 


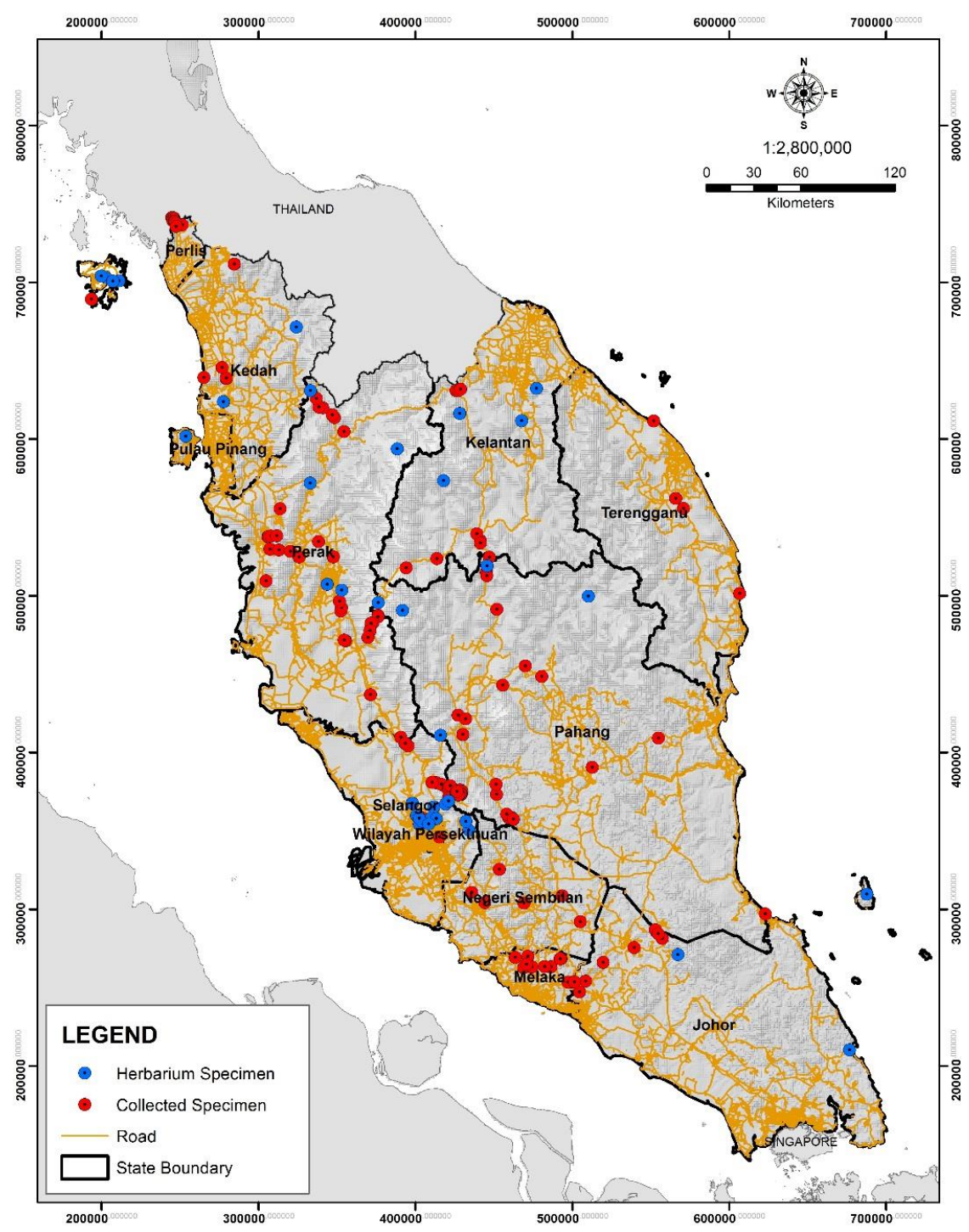

Figure 1: The distribution of M. tanarius in Peninsular Malaysia

Table 1: M. tanarius population observed in highlands and hill sites in Peninsular Malaysia

\begin{tabular}{lcc}
\hline Location & $\begin{array}{c}\text { Highest peak } \\
\text { (meter a.s.1.) }\end{array}$ & $\begin{array}{c}\text { Observed M. tanarius } \\
\text { (meter a.s.l) }\end{array}$ \\
\hline Gunung Jerai, Kedah & $1217 \mathrm{~m}$ & Up to $469 \mathrm{~m}$ \\
Maxwell Hill (Bukit Larut), Perak & $1250 \mathrm{~m}$ & Up to $320 \mathrm{~m}$ \\
Cameron Highland, Pahang & $1829 \mathrm{~m}$ & $228-1020 \mathrm{~m}$ \\
Fraser's Hill, Pahang & $1520 \mathrm{~m}$ & $280-677 \mathrm{~m}$ \\
Genting Highland, Pahang & $1865 \mathrm{~m}$ & $700-900 \mathrm{~m}$ \\
Bukit Tinggi, Pahang & $850 \mathrm{~m}$ & Up to $758 \mathrm{~m}$ \\
\hline
\end{tabular}

\section{CONCLUSION}

The current surveyed showed that $M$. tanarius has a wide distribution in Peninsular Malaysia except in the coastal sites of eastern region and the peat swamp area in the southern part of Johor. M. tanarius geographic distribution and population density depend on the environmental condition where they were sighted. Majority of the species were found at disturbed forest areas such as forest fringe, roadside, forest gap, riverbanks or swampy areas. The distribution of $M$. tanarius identified in this population survey may 


\section{The Distribution of Macaranga tanarius in Peninsular Malaysia}

change due to interference by human activities such as construction, or development of an area for housing or plantation. Most of the populations were found clusters and at low land areas. However, based on observations, there is a tendency that this species had shift to a higher elevation on hills and mountains. Understanding the distribution pattern of this species is important for its management and introduction as a plantation species. As $M$. tanarius flowers throughout the year, the problem of supply of planting material does not arise and suitable planting sites are plenty

\section{ACKNOWLEDGMENT}

The authors wish to thank Director General of FRIM for providing the research funding (Government of Malaysia under the $10^{\text {th }}$ Malaysia Plan). Special thanks to the Officers and Staff of Forest Biotechnology Division, FRIM whom involved directly and indirectly in the study.

\section{REFERENCES}

[1] Plant Resources of South-East Asia (PROSEA). 1998. No.5 (3) Lesser-known timbers; (eds). M.S.M. Sosef, L.T. Hong and S. Prawirohatmodjo. Backhuys Publishers, Leiden, The Netherlands.859p

[2] Whitmore, T. C. 1967. Studies in Macaranga, an easy genus of Malayan wayside trees. Malayan Nature Journal, 20(3): 89-99.

[3] Corner EJH. 1988. Wayside trees of Malaya. Vol. 1. Kuala Lumpur: Malayan Nature Society, 296304

[4] Jumaat H A. 1981. Macaranga (Euphorbiaceae) of Sabah and Sarawak. The Sarawak Museum Journal 23: 257-268.

[5] Davies S J, Palmiotto P A, Ashton P S, Lee H S and Lafrankies J V. 1998. Comparative ecology of 11 sympatric species of Macaranga in Borneo: Tree distribution in relation to horizontal and vertical resource heterogeneity. Journal of Ecology 86: 662-673.

[6] Slik J.W.F, Kebler P.J.A \& VAN Welzen P.C. 2003. Macaranga and Mallotus species (Euphorbiaceae) as indicators for disturbance in the mixed lowland dipterocarp forest of East Kalimantan (Indonesia). Ecological Indicators 2: 311-324.

[7] Turner I. 1989. An enumeration of one hectare of Pantai Aceh Forest Reserve, Penang. Garden Bulletin of Singapore 42(1): 29-44.

[8] Zakaria, R., Rosley, N. F. N., Mansor, M. \& Zakaria, M. Y. 2008. The distribution of
Macaranga, genus (family euphorbiaceae) in Penang Island, Peninsular Malaysia. Journal of Bioscience, 19(2): 91-99.

[9] Feldhaar H, Fiala B, RosII H \& Maschwitz U. 2000. Maintaining an ant-plant symbiosis: Secondary polygyny in the Macaranga trilobaCrematogaster sp. association. Naturwissenschaften 87: 408-411.

[10] Slik J W F, Kebler P J A and van Welzen P C. 2003. Macaranga and Mallotus species (Euphorbiaceae) as indicators for disturbance in the mixed lowland dipterocarp forest of East Kalimantan (Indonesia). Ecological Indicators 2: 311-324.

[11] Foresty Department Peninsular Malaysia. 2016. Forest type classification. https://www.forestry.gov.my/index.php/en/201606-07-02-31-39/2016-06-07-02-35-17/forest-type

[12] CABI. 2018. Macaranga tanarius (Parasol Leaf tree). In: Invasive Species Compendium, CABI Publishing,Wallingford,UK.ttps://www.cabi.org/is c/datasheet/32763

[13] Wagner W.L, Herbst D.R \& Sohmer S.H. 1999. Colocasia. In: Manual of the Flowering Plants of Hawaii. University of Hawaii Press, Honolulu, Hawai'i, pp. 1356-1357.

[14] Taylor, C. E. 1982. Reproductive biology and ecology of some tropical pioneer trees. $\mathrm{PhD}$ thesis. University of Aberdeen, Aberdeen, Scotland.

[15] Tseng Meihuims; Kuo Yuehhsiung; Chen Yihming; Chou Changhung, 2003. Allelopathic potential of Macaranga tanarius (L.) Muell.-Arg. Journal of Chemical Ecology, 29(5):1269-1286.

[16] World Agroforestry Centre, 2015. Macaranga tanarius.

Agroforestree

Database:atreereferenceandselectionguide.Version .http://www.worldagroforestry.org/treedb2/species profile.php?Spid=1092

[17] Abdul Wahab N. 1982. Masalah-masalah tanah bris. Teknologi Pertanian MARDI,3,81-91.

[18] Florabank. 2015. Florabank, Australian Government, Greening Australia and CSIRO. http://www.florabank.org.au/ 